\title{
Riscos ocupacionais no abate de bovinos: Classificação por grau de severidade
}

\author{
Occupational risks in cattle slaughter: Classification by severity degree \\ Riesgos ocupacionales no sacrificio de bovinos: Clasificación por grado de gravedad
}

Recebido: 08/04/2021 | Revisado: 14/04/2021 | Aceito: 15/04/2021 | Publicado: 29/04/2021

Camilla Nogueira de Souza
ORCID: https://orcid.org/0000-0003-4211-8181
E-mail: camilla.souza16@hotmail.com
Walmir Nunes Vieira Júnior
Instituto Federal de Educação, Ciência e Tenologia de Minas Gerais, Brasil
ORCID: https://orcid.org/0000-0003-3319-4940
Instituto Federal de Educação, Ciência e Tecnologia de Minas Gerais, Brasil
E-mail: walmirnunes@ hotmail.com

\begin{abstract}
Resumo
Introdução: o modo de trabalho empregado e as ferramentas utilizadas no processo produtivo da indústria frigorífica favorecem a ocorrência de acidentes ocupacionais e o surgimento de doenças respiratórias e musculoesqueléticas. Objetivo: identificar e classificar, quanto ao grau de severidade, os riscos existentes em uma indústria do ramo situada no município de Governador Valadares/MG. Métodos: A análise dos riscos foi realizada exclusivamente nas atividades ligadas ao abate de bovinos, abrangendo atordoamento, sangria, esfola, evisceração e corte da carcaça. A pesquisa se caracteriza como qualitativa e exploratória, e as informações referentes às condições de trabalho foram obtidas a partir de outro trabalho realizado no local pela autora. Assim sendo, quanto aos procedimentos técnicos, a pesquisa se caracteriza como revisão bibliográfica e estudo de caso. Resultados: A Análise Preliminar de Riscos APR possibilitou a identificação e classificação dos seguintes riscos: de ergonomia, de acidente, biológico, queda de mesmo nível, umidade, choque elétrico, ruídos e vibrações. Foram sugeridas medidas de intervenção para mitigar os riscos encontrados, observando a legislação trabalhista vigente. Conclusão: mediante a classificação é possível priorizar a tomada de medidas de prevenção nas atividades em que são encontrados riscos mais severos, como o uso de motosserra e um possível ataque do animal.
\end{abstract}

Palavras-chave: Segurança; Riscos; Frigorífico.

\begin{abstract}
Introduction: The way of working and the tools used during the production process of the slaughterhouse industry promotes the occurrence of occupational accidents and the rise of respiratory and musculoskeletal diseases. Objective: The objective is to identify and classify the existing risks regarding its severity degree, in a plant located in the city of Governador Valadares / MG. Methods: The risk analysis considered only activities related to the slaughter of cattle, including stunning, bleeding, skinning, evisceration and carcass cutting. The research is qualitative and exploratory, and all the information regarding working conditions were obtained from another research done by the same author at the same plant. Therefore, for technical procedures, the research is characterized as a bibliographic review and a case study. Results: The Preliminary Risk Analysis - PRA enabled the identification and classification of the following risks: ergonomic, accident, biological, falling from the same level, humidity, electric shock, noise and vibration. Intervention measures were suggested to mitigate the risks identified during the study, according to the current labor law. Conclusion: Through the risk's classification it is possible to prioritize the preventive measures at the activities where more severe risks were identified, such as the use of chainsaw and a possible attack of the animal.
\end{abstract}

Keywords: Security; Risks; Frigorific.

\section{Resumen}

Introducción: la forma de trabajo empleada y las herramientas utilizadas en el proceso productivo de la industria del matadero favorecen la ocurrencia de accidentes laborales y la aparición de enfermedades respiratorias y musculoesqueléticas. Objetivo: identificar y clasificar, en cuanto al grado de severidad, los riesgos que existen en una industria de la industria ubicada en la ciudad de Governador Valadares / MG. Métodos: El análisis de riesgo se realizó exclusivamente en actividades relacionadas con el sacrificio de ganado, incluyendo aturdimiento, sangrado, desollado, evisceración y despiece. La investigación se caracteriza por ser cualitativa y exploratoria, y la información sobre las condiciones de trabajo se obtuvo de otros trabajos realizados in situ por el autor. Por tanto, en cuanto a procedimientos técnicos, la investigación se caracteriza por ser una revisión bibliográfica y un estudio de caso. Resultados: El Análisis Preliminar de Riesgos - APR permitió identificar y clasificar los siguientes riesgos: ergonomía, accidentes, biológicos, caída desde el mismo nivel, humedad, descarga eléctrica, ruido y vibraciones. Se sugirieron medidas de intervención 
para mitigar los riesgos encontrados, respetando la legislación laboral vigente. Conclusión: a través de la clasificación es posible priorizar la toma de medidas preventivas en actividades donde se encuentran riesgos más severos, como el uso de una motosierra y un posible ataque por parte del animal.

Palabras clave: Seguridad; Rasguños; Nevera.

\section{Introdução}

A indústria frigorífica possui grande relevância no cenário econômico nacional, sendo responsável pela geração de inúmeros empregos e por levar produtos brasileiros a diversos países. Embora o avanço tecnológico tenha proporcionado a automatização de diversos processos, as atividades desenvolvidas nesse setor ainda requerem muito esforço manual (Sarda \& Kirtschig, 2009).

O trabalho é executado em linha de produção, onde cada funcionário é responsável pela realização de uma única tarefa e cada etapa depende da anterior. Em virtude da alta demanda, o ritmo de trabalho é intenso. O somatório do modo de trabalho empregado com as ferramentas utilizadas resulta em diversos riscos para os colaboradores (Souza, 2018)

Tendo em vista o contexto envolvido nesse ambiente de trabalho, buscou-se responder o seguinte questionamento: quais os riscos ocupacionais aos quais os trabalhadores ligados às atividades de abate estão expostos, de acordo com o grau de severidade, e quais medidas de prevenção e controle podem ser propostas, em observância às normas regulamentadoras de saúde e segurança do trabalho aplicáveis?

Para tanto, a Norma Regulamentadora $\mathrm{n}^{\circ} 36$ (Brasil, 2018b), que trata da segurança e saúde dos trabalhadores das empresas de abate e processamento de carnes e derivados, diz que é dever do empregador colocar em prática uma abordagem planejada, estruturada e global da prevenção, por meio do gerenciamento dos fatores de risco. Desta forma, para solução do problema, é pressuposto que a aplicação de uma técnica de análise de riscos seja a melhor ferramenta a fim de identificar, classificar quanto ao grau de priorização e propor medidas de controle aos riscos constatados nas atividades.

Este estudo tem como objetivo geral identificar e classificar, quanto ao grau de severidade, os riscos ocupacionais encontrados nas atividades de atordoamento, sangria, esfola, evisceração e corte da carcaça presentes em uma indústria de abate de bovinos situada no município de Governador Valadares/MG. Isto posto, serão contemplados como objetivos específicos a realização do levantamento das condições de trabalho no local, visando analisar as situações perigosas; aplicação da técnica denominada Análise Preliminar de Riscos - APR para identificação e classificação de severidade dos riscos ocupacionais; e por fim serão propostas medidas preventivas para os riscos identificados, em observância às Normas Regulamentadoras de Saúde e Segurança do Trabalho.

A importância desta pesquisa se justifica pelo número de acidentes registrados na indústria frigorífica nos últimos anos. De acordo com dados disponibilizados pela Secretaria Especial de Previdência e Trabalho, no Brasil, foram registradas em média 7.400 Comunicações de Acidentes de Trabalho - CAT por ano entre 2016 e 2018. Dentre os acidentes notificados durante o período, $90 \%$ correspondem a acidentes típicos da atividade, ou seja, ocasionados em decorrência da execução do trabalho, $7 \%$ equivalem aos acidentes de trajeto, e 3\% se referem a doenças ocupacionais (Brasil, 2020).

\section{Metodologia}

O objeto de estudo do trabalho é uma empresa frigorífica do município de Governador Valadares/MG. A coleta de dados foi realizada a partir de revisão bibliográfica em outra pesquisa executada por um dos autores no mesmo local, onde foram reunidas as informações referentes ao processo de abate e às condições de trabalho. Para realizar a classificação foi aplicada a técnica denominada Análise Preliminar de Riscos - APR. A pesquisa se caracteriza como qualitativa e exploratória, realizada mediante estudo de caso e revisão bibliográfica em livros e trabalhos científicos publicados em periódicos tais como SciELO e o portal de periódicos da CAPES, e em atenção às Normas Regulamentadoras de Saúde e Segurança do Trabalho 
aplicáveis às atividades.

\section{Referencial Teórico}

\section{Processo de abate de bovinos}

O processo de produção da carne bovina se inicia com o transporte dos bovinos ao frigorífico e vai até a expedição do produto final. A Figura 1 apresenta as principais etapas do processo de produção da carne bovina.

Figura 1. Principais etapas do processo de produção de carne bovina.

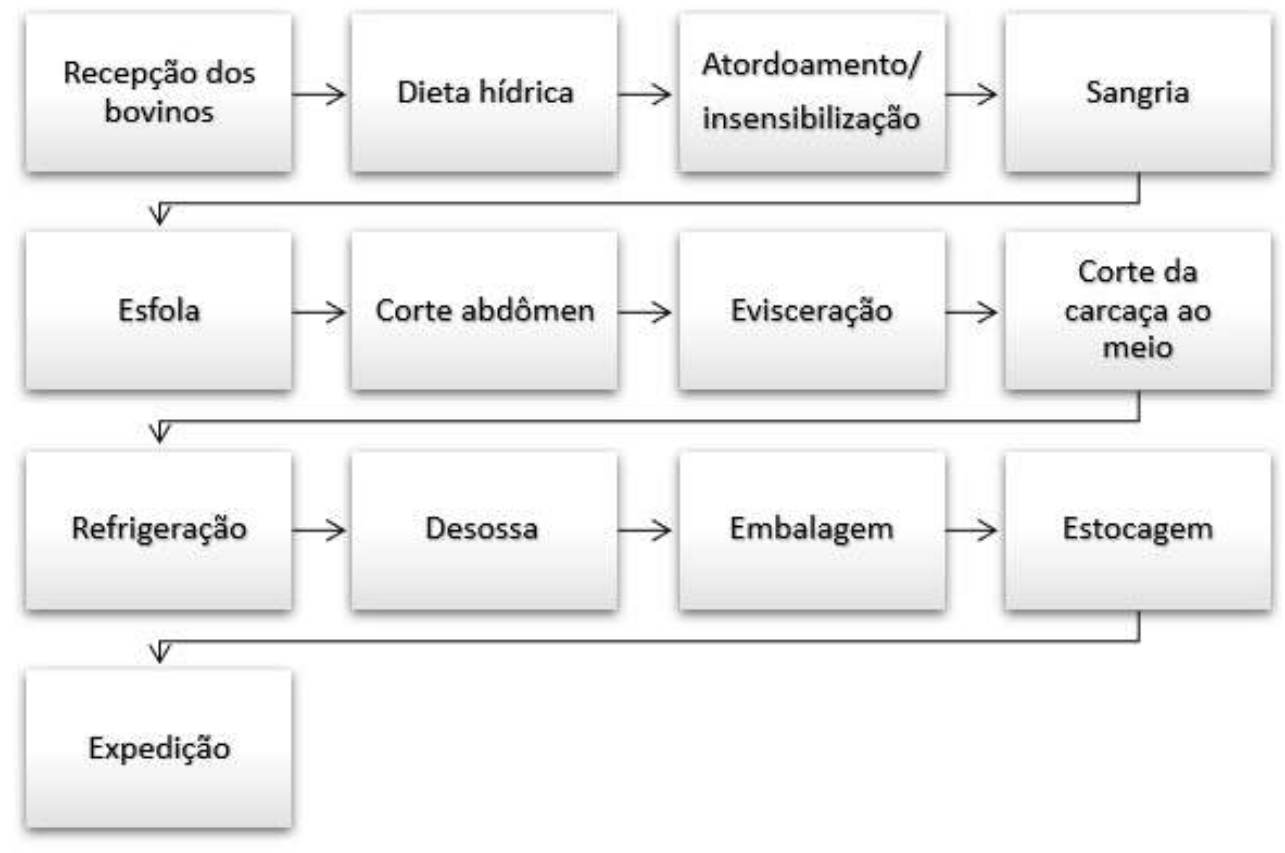

Fonte: Adaptado de Souza (2018).

Conforme Souza (2018), os animais chegam ao frigorífico geralmente no dia anterior ao abate, período no qual entram em jejum, consumindo apenas água por 24 horas. Durante este tempo, também passam por uma avaliação veterinária a fim de assegurar que estejam livres de quaisquer enfermidades que porventura possam tornar a carne imprópria para consumo.

A caminho da sala de matança, eles recebem o chamado banho de aspersão, que além de servir para higienizá-los, os acalma e ainda auxilia no aumento da pressão sanguínea, devido à água fria, o que contribui para um bom resultado no momento da sangria. Após a higienização, são encaminhados para o box de atordoamento (Souza, 2018).

Também conhecido como insensibilização, o atordoamento pode ser considerado a primeira fase para o abate propriamente dito. Essa operação consiste em possibilitar que o animal entre em um estado de inconsciência que perdure até o fim da sangria, para que não haja sofrimento desnecessário, esse estado de inconsciência é alcançado com o auxílio de uma pistola pneumática (Gil \& Durão, 1985). Ludtke et al. (2021) completa que o objetivo é deixar o animal inconsciente sem que haja transdução do estímulo da dor, a concussão cerebral o tornará inconsciente em milésimos de segundos.

Segundo Souza (2018), ao perder a consciência, o animal desaba e é comum que vomite, por isso logo após a queda recebe um jato de água para limpeza. Em seguida, é pendurado pelas patas traseiras e transportado por trilhos (nórias) até o local onde será realizada a sangria, que consiste em cortar os grandes vasos do pescoço do animal e deixar que o sangue escorra por uma calha. É este corte que causa efetivamente a morte. Silva (2012) informa que o processo de sangria dura aproximadamente 5 minutos, período no qual o animal perde cerca de $60 \%$ do seu sangue. 
Souza (2018) explica ainda que posteriormente à sangria ocorre a retirada dos chifres e patas e desarticulação da cabeça. Na sequência, é retirado o couro do animal, processo conhecido como esfola. Feito isso, o abdômen é serrado para a evisceração. Conforme Silva (2012), as vísceras são levadas para a triparia, enquanto as carcaças são serradas ao meio, lavadas e, por fim, refrigeradas em câmaras frias cujas temperaturas variam entre $0^{\circ}$ e $4^{\circ} \mathrm{C}$, onde ficam por um período entre 24 e 36 horas.

Após esse período, acontece o corte e a desossa das carcaças resfriadas, podendo ser divididas em porções menores para a comercialização ou processadas para produtos derivados (Amaral, 2010). Finalmente, os produtos são embalados, estocados e seguem para expedição.

\section{Condições de trabalho na indústria de abate de bovinos}

Iida (2005) alerta para os prejuízos que a automatização e mecanização dos processos produtivos trouxeram para a saúde do colaborador, embora tenha minimizado a carga de trabalho. Como exemplos, cita a manutenção de postura estática e inadequada, trabalho monótono e repetitivo, estresse causado pelo ritmo intenso e pressão por produção, entre outros.

Interessante notar que todas essas condições desfavoráveis citadas por Iida (2005) são encontradas no contexto de trabalho de um matadouro e frigorífico. Sarda e Kirtschig (2009) afirmam que a maioria das tarefas executadas neste ambiente são tidas como repetitivas, monótonas e fatigantes e podem acarretar problemas relacionados à saúde, conforto e segurança dos trabalhadores.

O processo produtivo de matadouros é organizado geralmente em linhas de produção, onde se utilizam máquinas, equipamentos e dispositivos de corte, o que por si só já representa considerável risco ocupacional (Marra, Neto \& Cardoso, 2017). Souza (2018) adverte ainda sobre os riscos de doenças musculoesqueléticas, favorecidos por este modo de trabalho.

Em suma, o modo de trabalho empregado e as ferramentas utilizadas na indústria frigorífica fazem com que haja variados tipos de riscos ao longo de todo o processo produtivo. Como agravante, há o fato de que, mesmo estando expostos a diversos riscos, o trabalho deve ser executado de forma rápida, uma vez que a pressão por produtividade é enorme e a linha de produção não para. Isso representa grande ameaça àqueles que se submetem a executar um serviço de forma acelerada em condições perigosas.

A Figura 2 traz um levantamento de condições perigosas encontradas nas etapas do processo de abate de bovinos que podem ocasionar acidentes ou doenças ocupacionais. 
Figura 2. Condições perigosas no processo de abate de bovinos.

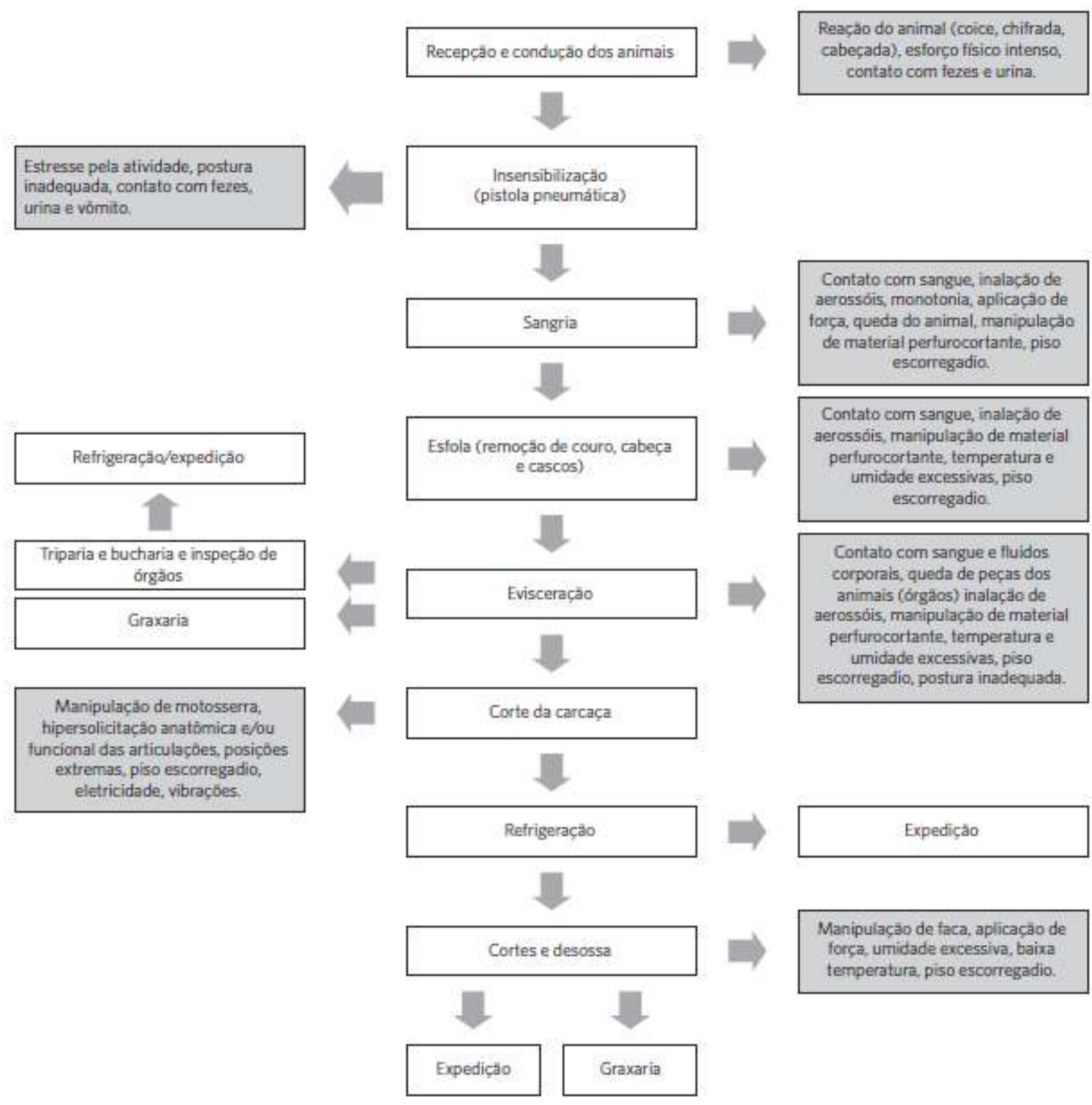

Fonte: Marra et al. (2017).

Para fins de pesquisa, optou-se por analisar mais profundamente os riscos encontrados nas atividades diretamente relacionadas ao abate. Assim sendo, este estudo está delimitado às atividades de atordoamento, sangria, esfola, evisceração e corte da carcaça.

\section{Técnicas de identificação e análise de riscos}

Prevenir acidentes e doenças no trabalho pressupõe uma atuação eficiente que os antecipe. Deve-se trabalhar para eliminar os fatores de risco logo nos primeiros sinais de ameaça à segurança ou à saúde do trabalhador, de forma a evitar que sejam concretizados (Vieira, Silva, Magno \& Toledo, 2020).

Existem várias ferramentas utilizadas para gerenciamento de riscos ocupacionais, como por exemplo: Análise Preliminar de Riscos - APR, Análise de Modos de Falha e Efeito - FMEA, Análise da Operabilidade de Perigos - HAZOP, entre outras. A aplicação dessas técnicas permite a identificação dos riscos de perdas acidentais existentes em determinado processo que ameaçam a organização (Ruppenthal, 2013). 
Para realização da presente pesquisa foi utilizada a ferramenta APR, que se trata de análise do tipo qualitativa que permite a identificação e avaliação dos riscos presentes em uma instalação ou unidade, permitindo ainda estabelecer responsabilidades no controle de risco, indicando sua relevância e prioridade a partir da categoria de severidade (Ruppenthal, 2013), conforme Quadro 1.

Quadro 1. Categoria de severidade dos efeitos.

\begin{tabular}{|l|l|}
\hline IV Catastrófica & $\begin{array}{l}\text { Morte, incapacidade permanente total, perda do equipamento/instalações, danos graves ao meio ambiente } \\
\text { (não recuperável), perda financeira elevada, danos elevados à imagem da empresa. }\end{array}$ \\
\hline III Crítica & $\begin{array}{l}\text { Lesões graves com incapacidade parcial grave, perda parcial do equipamento, danos sérios às instalações, } \\
\text { grandes perdas financeiras, danos sérios ao meio ambiente. }\end{array}$ \\
\hline II Marginal & $\begin{array}{l}\text { Lesões com incapacidade parcial leve, danos leves aos equipamentos e instalações, danos ao meio } \\
\text { ambiente facilmente recuperável, perdas financeiras indiretas e pequenas. }\end{array}$ \\
\hline I Desprezível & $\begin{array}{l}\text { lesões leves (tratamento médico e retorno imediato ao trabalho), danos leves aos equipamentos, não } \\
\text { prejudicial ao meio ambiente. }\end{array}$ \\
\hline
\end{tabular}

Fonte: De Cicco e Fantazzini (2003).

\section{Resultados e Discussão}

\section{Análise Preliminar de Riscos - APR}

Conforme a NR 36 (BRASIL, 2018b), o objetivo da avaliação de riscos é inserir medidas de prevenção para a mitigação ou eliminação dos mesmos, bem como investigar se as medidas previstas adotadas são adequadas, a fim de minimizar o impacto desses riscos à saúde e segurança dos colaboradores.

Considerando as condições de trabalho supracitadas e analisando as técnicas de gerenciamento de riscos ocupacionais, optou-se por utilizar a ferramenta denominada Análise Preliminar de Riscos - APR nas atividades de atordoamento, sangria, esfola, evisceração e corte da carcaça.

Para embasamento, foi utilizada outra pesquisa realizada pela autora no mesmo local, onde já haviam sido levantadas as condições de trabalho e as etapas do processo produtivo, concomitantemente em observação aos perigos elencados por Marra et al. (2017), conforme descrito na Figura 2.

Portanto, a APR foi desenvolvida identificando riscos, suas possíveis causas e efeitos. Além disso, foi avaliado o grau de severidade e estabelecidas medidas de prevenção e correção, observando as NRs 8, 12, 15, 17 e 36 . Isto posto, os resultados estão demonstrados no Quadro 2. 
Quadro 2. Análise Preliminar de Riscos.

\begin{tabular}{|c|c|c|c|c|c|}
\hline Etapa & Risco & Causa & Efeito & $\begin{array}{c}\text { Categoria } \\
\text { de } \\
\text { severidade }\end{array}$ & $\begin{array}{l}\text { Medidas preventivas ou } \\
\text { corretivas sugeridas }\end{array}$ \\
\hline \multirow[t]{2}{*}{ Atordoamento } & $\begin{array}{l}\text { Risco } \\
\text { ergonômico }\end{array}$ & $\begin{array}{l}\text { Postura } \\
\text { inadequada, } \\
\text { movimentos } \\
\text { repetitivos }\end{array}$ & Doenças musculoesqueléticas & II & $\begin{array}{c}\text { Revezamento de funções; } \\
\text { pausas durante a jornada } \\
\text { de trabalho; ginástica } \\
\text { laboral }\end{array}$ \\
\hline & $\begin{array}{l}\text { Risco de } \\
\text { acidente }\end{array}$ & Ataque do animal & Lesões/morte & IV & Barreiras físicas \\
\hline \multirow{5}{*}{ Sangria } & $\begin{array}{l}\text { Risco } \\
\text { ergonômico }\end{array}$ & $\begin{array}{l}\text { Postura } \\
\text { inadequada, } \\
\text { movimentos } \\
\text { repetitivos }\end{array}$ & $\begin{array}{l}\text { Doenças musculoesqueléticas, } \\
\text { fadiga física e mental }\end{array}$ & II & $\begin{array}{c}\text { Revezamento de funções; } \\
\text { pausas durante a jornada } \\
\text { de trabalho; ginástica } \\
\text { laboral }\end{array}$ \\
\hline & $\begin{array}{l}\text { Risco de } \\
\text { acidente }\end{array}$ & Uso de facas & Cortes & III & $\begin{array}{l}\text { Uso de EPI; treinamento } \\
\text { dos colaboradores; ritmo } \\
\text { de trabalho adequado }\end{array}$ \\
\hline & $\begin{array}{c}\text { Risco } \\
\text { biológico }\end{array}$ & $\begin{array}{l}\text { Contato com } \\
\text { sangue e vômito }\end{array}$ & Doenças & III & $\begin{array}{c}\text { Avaliação veterinária; uso } \\
\text { de EPI }\end{array}$ \\
\hline & $\begin{array}{l}\text { Queda de } \\
\text { mesmo nível }\end{array}$ & Piso escorregadio & Lesões & I & $\begin{array}{l}\text { Aplicação de materiais ou } \\
\text { processos antiderrapantes; } \\
\text { ralos de escoamento }\end{array}$ \\
\hline & Umidade & $\begin{array}{l}\text { Uso excessivo de } \\
\text { água }\end{array}$ & Doenças respiratórias, quedas & II & $\begin{array}{l}\text { Uso de EPI e EPC } \\
\text { (barreiras de contenção, } \\
\text { ralos de escoamento) }\end{array}$ \\
\hline \multirow{5}{*}{ Esfola } & $\begin{array}{l}\text { Risco } \\
\text { ergonômico }\end{array}$ & $\begin{array}{l}\text { Postura } \\
\text { inadequada, } \\
\text { movimentos } \\
\text { repetitivos }\end{array}$ & Doenças musculoesqueléticas & II & $\begin{array}{c}\text { Revezamento de funções; } \\
\text { pausas durante a jornada } \\
\text { de trabalho; ginástica } \\
\text { laboral }\end{array}$ \\
\hline & $\begin{array}{l}\text { Risco de } \\
\text { acidente }\end{array}$ & Uso de facas & Cortes & III & $\begin{array}{l}\text { Uso de EPI; treinamento } \\
\text { dos colaboradores; ritmo } \\
\text { de trabalho adequado }\end{array}$ \\
\hline & $\begin{array}{c}\text { Risco } \\
\text { biológico }\end{array}$ & $\begin{array}{l}\text { Contato com } \\
\text { sangue }\end{array}$ & Doenças & III & $\begin{array}{c}\text { Avaliação veterinária; uso } \\
\text { de EPI }\end{array}$ \\
\hline & $\begin{array}{l}\text { Queda de } \\
\text { mesmo nível }\end{array}$ & $\begin{array}{l}\text { Trabalho em } \\
\text { plataforma (menor } \\
\text { de } 2 \mathrm{~m} \text { ), piso } \\
\text { escorregadio }\end{array}$ & Lesões & I & $\begin{array}{c}\text { Aplicação materiais ou } \\
\text { processos antiderrapantes; } \\
\text { plataforma regulável; ralos } \\
\text { de escoamento }\end{array}$ \\
\hline & Umidade & $\begin{array}{l}\text { Uso excessivo de } \\
\text { água }\end{array}$ & Doenças respiratórias, quedas & II & $\begin{array}{c}\text { Uso de EPI e EPC } \\
\text { (barreiras de contenção, } \\
\text { ralos de escoamento) }\end{array}$ \\
\hline Evisceração & $\begin{array}{l}\text { Risco } \\
\text { ergonômico }\end{array}$ & $\begin{array}{l}\text { Postura } \\
\text { inadequada, } \\
\text { movimentos } \\
\text { repetitivos }\end{array}$ & Doenças musculoesqueléticas & II & $\begin{array}{c}\text { Revezamento de funções; } \\
\text { pausas durante a jornada } \\
\text { de trabalho; ginástica } \\
\text { laboral }\end{array}$ \\
\hline
\end{tabular}




\begin{tabular}{|c|c|c|c|c|c|}
\hline & $\begin{array}{l}\text { Risco de } \\
\text { acidente } \\
\text { Risco } \\
\text { biológico }\end{array}$ & $\begin{array}{l}\text { Manipulação de } \\
\text { motosserras } \\
\text { Contato com } \\
\text { sangue e fluidos } \\
\text { corporais }\end{array}$ & $\begin{array}{l}\text { Cortes/morte } \\
\text { Doenças }\end{array}$ & 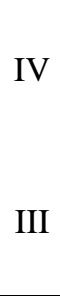 & $\begin{array}{c}\text { Uso de EPI; treinamento } \\
\text { dos colaboradores; ritmo } \\
\text { de trabalho adequado } \\
\text { Avaliação veterinária; uso } \\
\text { de EPI }\end{array}$ \\
\hline & $\begin{array}{l}\text { Queda de } \\
\text { mesmo nível }\end{array}$ & $\begin{array}{l}\text { Trabalho em } \\
\text { plataforma (menor } \\
\text { de } 2 \mathrm{~m} \text { ), piso } \\
\text { escorregadio }\end{array}$ & Lesões & I & $\begin{array}{c}\text { Aplicação materiais ou } \\
\text { processos antiderrapantes; } \\
\text { plataforma com barreiras } \\
\text { físicas; ralos de } \\
\text { escoamento }\end{array}$ \\
\hline & Umidade & $\begin{array}{l}\text { Uso excessivo de } \\
\text { água }\end{array}$ & Doenças respiratórias, quedas & II & $\begin{array}{c}\text { Uso de EPI e EPC } \\
\text { (barreiras de contenção, } \\
\text { ralos de escoamento) }\end{array}$ \\
\hline \multirow{7}{*}{ Corte carcaça } & $\begin{array}{l}\text { Risco } \\
\text { ergonômico }\end{array}$ & $\begin{array}{l}\text { Uso excessivo de } \\
\text { força e postura } \\
\text { inadequada }\end{array}$ & Doenças musculoesqueléticas & II & $\begin{array}{c}\text { Revezamento de funções; } \\
\text { pausas durante a jornada } \\
\text { de trabalho; ginástica } \\
\text { laboral }\end{array}$ \\
\hline & $\begin{array}{l}\text { Risco de } \\
\text { acidente }\end{array}$ & $\begin{array}{l}\text { Manipulação de } \\
\text { motosserra }\end{array}$ & Cortes/morte & IV & $\begin{array}{l}\text { Uso de EPI; treinamento; } \\
\text { dispositivos de segurança } \\
\text { conforme NR } 12\end{array}$ \\
\hline & $\begin{array}{c}\text { Risco } \\
\text { biológico }\end{array}$ & $\begin{array}{l}\text { Contato com } \\
\text { sangue }\end{array}$ & Doenças & III & $\begin{array}{c}\text { Avaliação veterinária; uso } \\
\text { de EPI }\end{array}$ \\
\hline & $\begin{array}{l}\text { Risco de } \\
\text { choque } \\
\text { elétrico }\end{array}$ & $\begin{array}{l}\text { Uso de motosserra } \\
\text { em ambiente com } \\
\text { água }\end{array}$ & Morte & IV & $\begin{array}{c}\text { Uso de EPI e EPC; } \\
\text { manutenções preventivas } \\
\text { do maquinário }\end{array}$ \\
\hline & $\begin{array}{l}\text { Queda de } \\
\text { mesmo nível }\end{array}$ & $\begin{array}{l}\text { Trabalho em } \\
\text { plataforma (menor } \\
\text { de } 2 \mathrm{~m} \text { ), piso } \\
\text { escorregadio }\end{array}$ & Lesões & I & $\begin{array}{l}\text { Aplicação materiais ou } \\
\text { processos antiderrapantes; } \\
\text { plataforma com barreiras } \\
\text { físicas; ralos de } \\
\text { escoamento }\end{array}$ \\
\hline & Umidade & $\begin{array}{l}\text { Uso excessivo de } \\
\text { água }\end{array}$ & Doenças respiratórias, quedas & II & $\begin{array}{c}\text { Uso de EPI e EPC } \\
\text { (barreiras de contenção, } \\
\text { ralos de escoamento) }\end{array}$ \\
\hline & $\begin{array}{l}\text { Ruídos e } \\
\text { vibrações }\end{array}$ & $\begin{array}{l}\text { Manipulação de } \\
\text { motosserra }\end{array}$ & $\begin{array}{l}\text { Alterações neurovasculares, } \\
\text { problemas nas articulações, } \\
\text { lesões, perda auditiva parcial } \\
\text { ou total }\end{array}$ & II & $\begin{array}{c}\text { Aferir níveis de ruído e } \\
\text { vibração }\end{array}$ \\
\hline
\end{tabular}

Fonte: Autores (2020).

A APR tem como principal objetivo classificar os riscos conforme o grau de severidade, possibilitando priorizar aqueles cujos efeitos são mais graves. Assim sendo, a análise dos resultados será apresentada seguindo este critério, do maior ao menor grau.

\section{Grau de severidade IV - Catastrófica}

Os riscos de acidentes causados pela manipulação de motosserra nas atividades de evisceração e corte da carcaça, assim como por um possível ataque do animal antes do atordoamento, apresentam-se como riscos de maior grau de severidade. 
Também é necessário citar o risco elétrico envolvido nas atividades em que é necessário o uso de motosserra, ocasionado pela manipulação da mesma em um ambiente com muita umidade. Como consequência podemos citar lesões, cortes, choque elétrico e óbito.

A Norma Regulamentadora n 12 (Brasil, 2019), que trata da segurança no trabalho em máquinas e equipamentos, em seu anexo $\mathrm{V}$, apresenta os itens de prevenção de acidentes que devem, obrigatoriamente, constar nas motosserras, sendo eles: freio manual ou automático de corrente, pino pega-corrente, protetor da mão direita, protetor da mão esquerda e trava de segurança do acelerador. Além disso, a NR também exige que sejam promovidos treinamentos com carga horária mínima de oito horas a todos os operadores.

De acordo com a Norma Regulamentadora n 36 (Brasil, 2018b), durante atividade de atordoamento é necessária a existência de dispositivos visando a retenção do animal, objetivando a segurança do trabalhador no caso de eventual falha no procedimento. Em relação ao risco de choque elétrico, a NR apresenta que todas as instalações elétricas das máquinas e equipamentos devem ser projetadas e mantidas de forma a prevenir o risco, atendendo às disposições contidas na NR 12 e na NR 10, que visa a segurança em instalações e serviços em eletricidade.

\section{Grau de severidade III - Crítica}

Grande parte das atividades em um frigorífico requerem o uso de facas. Na sangria e esfola, elas são as principais ferramentas de trabalho. A probabilidade de que os trabalhadores se cortem no desenvolvimento dessas atividades fez com que elas fossem consideradas críticas. O uso de EPI, o treinamento dos funcionários e o ritmo adequado de trabalho são essenciais para que estes riscos sejam reduzidos.

A Norma Regulamentadora $n^{\circ} 36$ (Brasil, 2018b) dispõe sobre as condições de uso de facas, elencando a necessidade de que estas possuam tipo, formato e a textura da empunhadura apropriada à tarefa, à mão do trabalhador e ao eventual uso de luvas. A NR também exige a implementação de sistema de controle de afiação das facas e a reposição destas em função da demanda de produção, assim como o treinamento dos colaboradores envolvidos na atividade.

Outro risco considerado crítico foi o risco biológico presente nas atividades de sangria, esfola, evisceração e corte das carcaças, existente em virtude do contato com sangue e outros fluidos corporais do animal e, consequentemente, da exposição a agentes biológicos como fungos, bactérias, vírus, etc. O contato direto com esses fluidos pode desencadear doenças, por isso, é muito importante que os profissionais usem uniforme, máscara e demais EPIs.

\section{Grau de severidade II - Marginal}

Ao elaborar a APR, prontamente foi possível perceber a existência de risco ergonômico em todas as etapas analisadas. Isso ocorre principalmente devido ao modo de trabalho adotado, como mencionado anteriormente. Uma vez que as tarefas são executadas em linha de produção, cada colaborador é responsável por apenas uma função, e a faz repetidamente durante toda jornada de trabalho. Além disso, assumem posturas inadequadas ao desempenhar suas atividades. Esse conjunto de fatores contribui para que seja grande a propensão a contraírem doenças musculoesqueléticas, o que foi classificado como grau de severidade II.

A NR 17 (Brasil, 2018a), que trata de ergonomia, prevê pausas para descanso nesse tipo de atividade. A fim de minimizar os efeitos dessas condições, sugere-se também a prática de ginástica laboral no início da jornada de trabalho, assim como o revezamento de funções, para que o trabalhador não fique desempenhando uma mesma tarefa por um longo período.

A umidade excessiva, presente principalmente nas atividades de sangria, esfola, evisceração e corte da carcaça, também foi classificada como grau de severidade II por favorecer a contração de doenças respiratórias. Conforme o Anexo X da NR 15 (Brasil, 2018), tais atividades são capazes de causar danos à saúde dos trabalhadores e poderão ser consideradas 
insalubres. O uso de EPI e EPC como formas de barreiras, assim como ralos de escoamento da água, são primordiais para amenizar o risco.

Por fim, os ruídos e vibrações resultantes da manipulação de motosserra nas atividades de evisceração e corte da carcaça também se enquadram nessa categoria pela possibilidade de causar alterações neurovasculares, problemas nas articulações, lesões e perda auditiva parcial ou total. Por isso, é de extrema importância aferir os níveis de ruído e vibrações, cujos limites devem ser informados pelos fabricantes da ferramenta (Brasil, 2018).

\section{Grau de severidade I - desprezível}

Outro risco muito presente nas atividades de abate é o de queda de mesmo nível (menor que $2 \mathrm{~m}$ ), em função do trabalho ser muitas vezes executado em cima de plataformas e desenvolvido em um ambiente com muita água, o que pode tornar o piso escorregadio. Pelas plataformas estarem a uma altura razoável, as lesões provenientes das possíveis quedas fizeram com que o risco fosse classificado com grau de severidade I. Ralos de escoamento para água, barreiras físicas nas plataformas e processos antiderrapantes contribuem para um ambiente mais seguro. Este risco é abordado pela NR ${ }^{\circ} 08$ (Brasil, 2011), que estabelece a obrigatoriedade de aplicação de materiais ou processos antiderrapantes em pisos, escadas, rampas, corredores e passagens de trabalho onde houver risco de escorregamento. A NR ainda estipula que os pisos e paredes dos locais de trabalho, sempre que necessário, devem ser impermeabilizados e protegidos contra umidade.

\section{Considerações Finais}

Mediante a elaboração da APR foi possível constatar os riscos que os trabalhadores envolvidos nas atividades de atordoamento, sangria, esfola, evisceração e corte da carcaça estão expostos. Outrossim, foi possível compreender a gravidade de danos por meio da classificação por grau de severidade, permitindo visualizá-los por ordem de prioridade, facilitando assim a tomada de decisões objetivando assegurar a saúde e segurança dos colaboradores.

As medidas preventivas sugeridas na APR poderão ser aplicadas no cotidiano de trabalho da empresa estudada, bem como em outras do mesmo ramo, visando a extinção ou minimização dos riscos presentes no ambiente laboral. As percepções acerca das condições de trabalho observadas neste estudo também podem colaborar com pesquisas científicas realizadas sobre a indústria frigorífica no país.

Vale ressaltar que foram abordadas exclusivamente algumas atividades relacionadas ao abate dos bovinos, sendo necessárias outras pesquisas para identificar os perigos e os riscos nas demais etapas do processo. Sugere-se que a partir das considerações levantadas neste artigo, outras pesquisas busquem aperfeiçoar os métodos de produção, no que tange à segurança ocupacional, com enfoque nas particularidades de cada atividade.

\section{Referências}

Amaral, P. H. (2010). Programas de autocontrole em um matadouro-frigorífico de bovinos (Monografia Graduação). Universidade Federal do Rio Grande do Sul.

Brasil. (2020). Anuário Estatístico de Acidentes do Trabalho - AEAT. Ministério da Economia. Brasília, DF.

Brasil. (2011). NR 08: Edificações. Normas Regulamentadoras de Segurança e Medicina do Trabalho. Ministério do Trabalho e Emprego. Brasília, DF.

Brasil. (2019). NR 12: Segurança no trabalho em máquinas e equipamentos. Normas Regulamentadoras de Segurança e Medicina do Trabalho. Ministério do Trabalho e Emprego. Brasília, DF.

Brasil. (2018). NR 15: Atividades e operações insalubres. Normas Regulamentadoras de Segurança e Medicina do Trabalho. Ministério do Trabalho e Emprego. Brasília, DF.

Brasil. (2018a). NR 17: Ergonomia. Normas Regulamentadoras de Segurança e Medicina do Trabalho. Ministério do Trabalho e Emprego. Brasília, DF. 
Research, Society and Development, v. 10, n. 5, e10010514800, 2021

(CC BY 4.0) | ISSN 2525-3409 | DOI: http://dx.doi.org/10.33448/rsd-v10i5.14800

Brasil. (2018b). NR 36: segurança e saúde no trabalho em empresas de abate e processamento de carnes e derivados. Normas Regulamentadoras de Segurança e Medicina do Trabalho. Ministério do Trabalho e Emprego. Brasília, DF.

De Cicco, F., \& Fantazzini M. L. (2003). Tecnologias consagradas de gestão de riscos: riscos e probabilidades. Séries Risk Management.

Gil, J. I., \& Durão, J. C. (1985). Manual de inspeção sanitária de carnes. Fundação Caloustre Gulbenkian.

Iida, I. (2005). Ergonomia: Projeto e Produção (2a ed). Edgard Blucher.

Ludtke, C. B., Ciocca, J. R. P., Dandin, T., Barbalho, P. C., Vilela, J. A., \& Ferrarini, C. (2012). Abate humanitário de bovinos. WSPA.

Marra, G. C., Cohen, S. C., Neto, F. P. B., \& Cardoso, T. A. O. (2017). Avaliação dos riscos ambientais na sala de abate de um matadouro de bovinos. Saúde Debate, 41, 175-187.

Ruppenthal, J. E. (2013). Gerenciamento de riscos. Rede e-Tec Brasil.

Sarda, S. E., Ruiz, R. C., \& Kirtschig, G. (2009). Tutela jurídica da saúde dos empregados de frigoríficos: considerações dos serviços públicos. Revista Acta Fisiátrica, 16(2): 59-65.

Silva, B. V. C. (2012). Abate Humanitário e o bem-estar animal em bovinos (Monografia Graduação). Universidade Federal do Rio Grande do Sul.

Souza, C. N. (2018). Análise ergonômica com enfoque em biomecânica ocupacional: estudo de caso em um matadouro e frigorífico em Governador Valadares - MG (Monografia Graduação). Instituto Federal de Educação, Ciência e Tecnologia de Minas Gerais, Governador Valadares.

Vieira, A. A., Silva, Â. R. da, Magno, J. C., \& Toledo, L. L. de M. (2020). Gerações Y e Z e suas percepções de riscos de segurança e saúde no trabalho. Research, Society and Development, 9(7), e297973767. https://doi.org/10.33448/rsd-v9i7.3767 